\title{
ANÁLISE DO CURSO DE ENGENHARIA INDUSTRIAL DA UFPA ABAETETUBA EMPREGANDO O MÉTODO SERVQUAL NA PERCEPÇÃO DISCENTE
}

\author{
Harley dos santos MARTINS ${ }^{1}$ \\ Universidade Federal do Pará-UFPA \\ Beatriz Cardoso LOBATO2 \\ Universidade Federal de Santa Maria - UFSM \\ Ismael Gomes dos SANTOS ${ }^{3}$ \\ Universidade Federal do Pará-UFPA \\ Andreza Negrão MELO ${ }^{4}$ \\ Universidade Federal do Pará-UFPA \\ Stefane Dias RODRIGUES ${ }^{5}$ \\ Universidade Federal do Pará -UFPA
}

Resumo: $O$ objetivo deste trabalho é desenvolver uma pesquisa quantitativa, fazendo levantamento das expectativas $e$ percepções dos alunos de engenharia industrial em relação ao curso. Os dados da pesquisa foram coletados a partir de aplicação de questionários online, utilizando a ferramenta googleforms, e questionários impressos. As informações coletadas foram tabuladas calculando-se assim os gaps para analisar pontos negativos e positivos, onde se destaca que as maiores lacunas encontradas foram os itens que tratam da cantina (-1,264), divulgação de informações de eventos e serviços de interesse aos discentes (-1,321) $e$ laboratórios específicos do curso $(-1,377)$. Por fim, utilizando a ferramenta da qualidade $5 \mathrm{WlH}$, se propôs um plano de ação para aperfeiçoar processos e evitar erros e insatisfações.

Palavras-chave: SERVQUAL, Ensino Superior, Qualidade.

\begin{abstract}
The objective of this work is the development of a quantitative research, surveying the expectations and perceptions of students of industrial engineering in relation to the course. The survey data was collected from online questionnaire applications, using a googleforms tool, and printed questionnaires. The information gathered was tabulated, thus calculating gaps for negative and positive points, highlighting gaps in items dealing with the canteen (-1,264), dissemination of information on events and services of interest to students $(-1,321)$ and specific laboratories (-1,377). Using the $5 \mathrm{WlH}$ quality tool, an action plan was developed for the improvement process and to avoid errors and dissatisfactions..
\end{abstract}

Keywords: SERVQUAL, Higher Education, Quality.

\footnotetext{
${ }^{1}$ Doutorado em Engenharia e Gestão Industrial pela Universidade de Aveiro - UA (2014) em Portugal. Professor da UFPA - Campus de Abaetetuba. E-mail: harleymartins@yahoo.com.br

2 Graduada em Engenharia Industrial pela Universidade Federal do Pará (UFPA). Atualmente é aluna do mestrado em Engenharia de Produção da Universidade Federal de Santa Maria (UFSM).

${ }^{3}$ Possui graduação em Licenciatura Plena em Matemática pela Universidade do Estado do Pará (2011). Possui também Graduação em Engenharia Industrial e Especialização em Engenharia da Qualidade, ambas pela Universidade Federal do Pará (2018).

${ }^{4}$ Graduada em Engenharia Industrial pela Universidade Federal do Pará - UFPA e graduada em Pedagogia pela Faculdade Integrada de Araguatins.

${ }^{5}$ Graduada em Engenharia Industrial pela Universidade Federal do Pará - UFPA.
} 


\section{Introdução}

O mercado de trabalho vem sendo cada vez mais exigente com a contratação de seus funcionários, a busca por profissionais bem qualificados vem se tornando um desafio para os empresários. A formação superior acaba em algumas instituições se tornando requisito básico para contratação, muitas empresas vão buscar dados e informações das intuições de ensino frequentadas por seus colaboradores para ter base de que tipo de formação eles tiveram e como isso será promissor em sua empresa.

Levando em conta esta visão a importância por ter excelência em uma instituição e em seus cursos serve não só como um diferencial, mas um requisito de aceitação de seus estudantes. A avaliação na qualidade do serviço, com o modelo SERVQUAL, se apresenta como uma ferramenta avaliativa que oferece parâmetros para tomada de decisão e a partir da opinião de seus usuários verificar os pontos que devem ser trabalhados e melhorados para que se tenha a qualidade esperada por seus alunos.

Logo, este trabalho tem como objetivo avaliar quantitativamente, através da ferramenta do SERVQUAL, a expectativa e a percepção dos alunos do curso de engenharia industrial em relação a diversos aspectos do mesmo, coletando dados através de questionários impressos e onlines utilizando a ferramenta googledocs aplicados a todas as turmas de engenharia, podendo-se assim calcular os gaps e propor soluções para os eventuais problemas utilizado a ferramenta $5 \mathrm{~W} 1 \mathrm{H}$.

\section{Metodologia}

O método de estudo utilizado no presente artigo segue uma lógica de aplicação baseada e adaptada de dois estudos publicados pelos autores Oliveira \& Ferreira (2008) e Marques \& Pierre (2014). Na metodologia aqui empregada, no período de Março a Outubro de 2017, abrangendo as turmas EI 2012, EI 2013, EI 2014, EI 2015 e EI 2016, foram realizadas as aplicações de questionários a 106 alunos do curso de Bacharelado em Engenharia Industrial do Campus UFPA na cidade de Abaetetuba, objetivando uma avaliação da satisfação dos alunos quanto ao serviço prestado pelo curso.

Dividindo-se em cinco etapas, a metodologia teve na primeira etapa a realização de um breve estudo teórico acerca de temas relevantes para a pesquisa, tais como o conceito de qualidade, conceito de serviço, o modelo de avaliação da qualidade em serviços de Parasuraman, Zeithaml e Berry, denominado de modelo SERVQUAL.Na segunda etapa, elaborou-se um questionário do modelo SERVQUAL, subdividido em MARGENS - Revista Interdisciplinar 
duas seções com 35 questões cada (Apêndice A). Na primeira seção, as questões listadas dizem respeito as percepções, em quanto que a segunda seção aborda as expectativas relevantes aos entrevistados, no que diz respeito ao seu grau de satisfação com os serviços prestados pelo curso, alvo do estudo.

Durante a terceira etapa, efetuou-se as coletas de dados em dois momentos, no primeiro momento o questionário foi impresso para uma coleta de dados em uma abordagem boca a boca com os alunos do curso. No segundo momento, os questionários respondidos pelos alunos foram lançados no sistema googleforms.

Na quarta etapa, utilizou-se o software Microsoft Excel 2016, para a construção da planilha, em qual foram lançadas as respostas dos questionários. Pela formulação de equações, efetuou-se os cálculos dos gaps referentes a cada dimensão do questionário. A avaliação do gap de cada item foi feita pela média aritmética das notas atribuídas (numa escala de 1 a 5 , onde 1 representa a insatisfação e 5 a satisfação) pelos discentes tanto na expectativa quanto com a percepção de um serviço. Deste modo, a determinação do gap de uma dimensão i é feita pela diferença entre a sua percepção $\mathrm{P}(\mathrm{i})$ e a sua expectativa E(i) sobre o serviço para cada dimensão do estudo, gerando deste modo a equação:

Gap(i) = Média das Notas das P(i) - Média das Notas das E(i).

Por fim, na quinta etapa, realizou-se a análise geral observando-se os itens que apresentaram os piores índices, tendo uma alta negatividade, para o desenvolvimento das propostas de melhoria por meio da utilização da ferramenta $5 \mathrm{~W} 1 \mathrm{H}$, conclusões e apresentação dos resultados.

\section{Referencial teórico}

Nesta seção, será realizada uma breve abordagem sobre os conceitos de qualidade, serviço e sobre o modelo de avaliação da qualidade em serviços, SERVQUAL, de Parasuraman, Zeithaml e Berry.

\section{Qualidade}

Para começar a abordar o assunto qualidade é importante saber seus conceitos. Segundo Carvalho e Paladini (2012), qualidade é a relação existente entre a empresa e o mercado, ou seja, é saber o quanto o cliente ou consumidor espera e quanto a organização atende às suas expectativas. 
Qualidade também pode ser definida pela satisfação do cliente quanto ao serviço ou produtos que dependerá de sua expectativa sobre os mesmos e sobre a sua percepção ao adquiri-los, logo assim existirá a satisfação quando a percepção superar a expectativa e logicamente insatisfação se ocorre o contrário (CARPINETTI \& GEROLAMO, 2016).

A qualidade é de suma importância dentro das organizações e indica quando um método ou sistema é eficaz, e, serve como fator decisivo para definir o que permanece ou não dentro do mercado competitivo. Focar na satisfação do cliente conta como marco para empresas e instituições que queriam se consolidar no mercado e ganhar a confiança da população, logo focar na qualidade em todos seus parâmetros faz com as instituições se destaquem e ganhe fidelização.

Trabalhar o serviço prestado aos clientes desde a realização do pedido até o pósvenda dará parâmetros para que se possa saber as expectativas e as percepções do cliente em relação ao produto ou serviço que recebeu, e assim aperfeiçoar os procedimentos para evitar erros e falhas. Tendo esses conceitos de qualidade e sua importante relação com serviço, o próximo tópico abordará serviço e algumas suas características.

\section{Serviço}

O conceito de serviço é atribuído por muitos autores como sendo de natureza intangível, por exemplo, Fitzsimmons \& Fitzsimmons (2007) afirmam que o serviço é uma experiência vivenciada pelo cliente, que é o propósito da criação do mesmo, de forma efêmero e intangível. Grönroos (1993) diz que a ocorrência do serviço pode acontecer ou não com a presença do consumidor e o empregador durante as transações, e também, que o que caracteriza o serviço é uma ou mais atividades que podem ser mais ou menos tangível.

No entanto, além de entender o serviço é necessário avaliá-lo, pois para mensurar o nível de satisfação do cliente é necessário conhecer a qualidade do serviço. Segundo Las Casas (1997), a qualidade em serviço é medida pela satisfação do consumidor que vivenciou uma experiência através de uma atividade a ele fornecida, sendo que esta proporciona a satisfação de uma necessidade, seja como solução de um problema ou como fornecimento de um benefício. Assim, percebe-se que existe a necessidade de compreensão de serviço e de avaliar a satisfação do mesmo, pois através disso é possível a análise do objeto de estudo. 


\section{O modelo de avaliação da qualidade em serviços de Parasuraman, Zeithaml e Berry}

No ano de 1985, três norte-americanos, A. Parasuraman, Valarie A. Zeithaml e Leonard L. Berry, desenvolveram um estudo que visava compreender a ótica com que os clientes ponderam e entendem a qualidade dos serviços. Este estudo levou em consideração quatro cenários distintos em prestação de serviços, que tornou visíveis os critérios de avaliação (dimensões do processo de avaliação) utilizados pelos usuários, independente do serviço analisado. Estes critérios totalizaram-se em dez dimensões (PARASURAMAN, ZEITHAML \& BERRY, 1985).

No quadro 1, estão listados e discriminados os critérios identificados pela pesquisa de Parasuraman, Zeithaml e Berry segundo Pena et al. (2013).

Quadro 1 - Dez dimensões do processo de avaliação da qualidade de serviços

\begin{tabular}{|l|l|}
\hline Tangibilidade & $\begin{array}{l}\text { Aparência física das instalações, equipamentos, quadro de } \\
\text { trabalhadores e matérias normativos. }\end{array}$ \\
\hline Confiabilidade & $\begin{array}{l}\text { Capacidade de realizar o serviço prometido de forma confiável e com } \\
\text { precisão. }\end{array}$ \\
\hline Responsividade & Capacidade para ajudar os usuários com prontidão \\
\hline Competência & $\begin{array}{l}\text { Apropriação das habilidades requeridas e conhecimento para realizar } \\
\text { serviços. }\end{array}$ \\
\hline Cordialidade & Polidez, respeito, considerações e amistosidade de trabalhadores \\
\hline Credibilidade & Confiança, verdade honestidade \\
\hline Segurança & Ausência de perigo, risco ou dúvida. \\
\hline Acessibilidade & Proximidade e contato empático \\
\hline Comunicação & Manter os usuários informados numa linhagem adequada \\
\hline Compreensão & Esforça-se para entender o usuário e suas necessidades \\
\hline
\end{tabular}

De acordo com Parasuraman, Zeithaml e Berry (1985), ao ser feita a análise estatística dos dados do estudo, as dimensões apresentadas no quadro 1 reduziram-se a apenas 5 dimensões. Estas dimensões podem ser visualizadas e comparadas com as dez dimensões originais no quadro 2.

Quadro 2 - Comparação das dimensões reestruturadas e originais

\begin{tabular}{|l|l|}
\hline Dimensão reestruturada & Dimensões originais \\
\hline Tangibilidade & Tangibilidade \\
\hline Confiabilidade & Confiabilidade \\
\hline Responsividade & Responsividade \\
\hline \multirow{3}{*}{ Garantia } & Competência \\
\cline { 2 - 2 } & Cordialidade \\
\cline { 2 - 2 } & Credibilidade \\
\hline
\end{tabular}




\begin{tabular}{|l|l|}
\hline & Segurança \\
\hline \multirow{4}{*}{ Empatia } & Acessibilidade \\
\cline { 2 - 2 } & Comunicação \\
\cline { 2 - 2 } & Compreensão \\
\hline
\end{tabular}

Fonte: Adaptado de Pena et al. (2013)

Segundo Pena et al. (2013), as cinco dimensões reestruturadas passam a ter as seguintes definições:

- Tangibilidade: é entendido como a dimensão que avalia tudo o que é palpável e com o qual o homem pode interagir usando os seus cinco sentidos, como exemplo, pode-se citar, equipamentos, instalações físicas, entre outros.

- Confiabilidade: é a dimensão, na qual, o usuário avalia se um serviço foi executado de forma segura e eficiente sem apresentar não conformidades e sem precisar de retrabalhos, em resumo, é a dimensão que avalia o quanto um serviço é confiável.

- Responsividade: é a dimensão que trata da pronta disposição dos prestadores de serviços e capacidade de respostas, para o atendimento dos usuários de forma voluntária, atenciosa, precisa e rápida.

- Garantia: é a dimensão que diz respeito às habilidades e conhecimentos dos prestadores de serviço, de forma cordial, passando aos usuários confiança e segurança.

- Empatia: é a dimensão que trada da importância que o usuário representa para a prestadora do serviço e do quanto esta se interessa por ele, lhe dando atenção, acessibilidade e sensibilidade se esforçando para entender as necessidades apresentadas pelos usuários.

Segundo Parasuraman, Zeithaml e Berry (1991), verificou-se também com a análise dos resultados do estudo realizado, a existência dos chamados Gaps, lacunas ou discrepâncias que se originam na diferença entre o nível de serviço percebido e o nível de serviço esperado pelo usuário, essa discrepância entre a percepção e a expectativa do serviço determinará se a prestação do serviço apresenta qualidade, Gap positivo, ou não, Gap negativo e em que grau.

Os Gaps comentados anteriormente podem facilmente ser representados pelo esquema apresentado na Figura 1. 
Figura 1 - Esquema dos Gaps

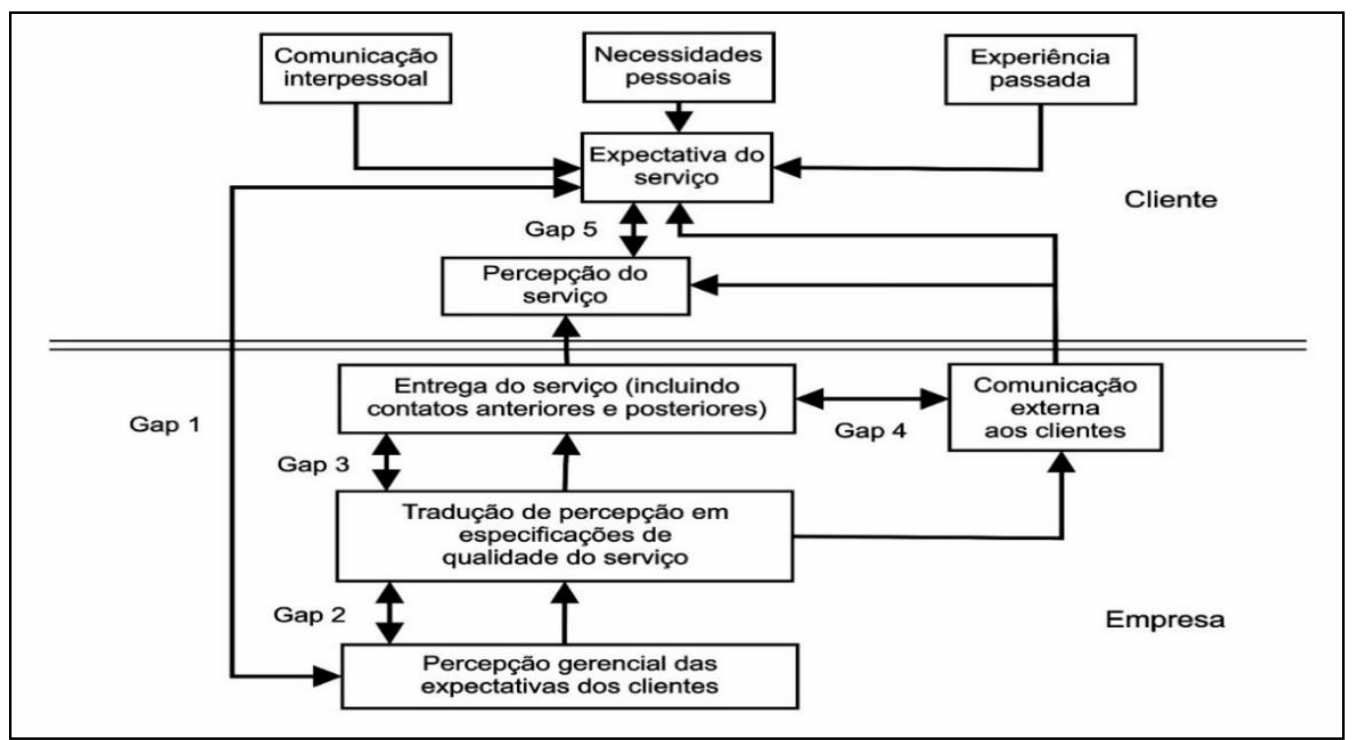

Fonte: Adaptado de Parasuraman, Zeithaml \& Berry (1985).

Os Gaps, já citados, podem ser definidos como:

- Gap 1: é entendido como a discrepância apresentada entre as percepções dos executivos e as expectativas dos usuários, originada pela identificação, de forma errada, das verdadeiras expectativas dos usuários.

- Gap 2: é entendido como a discrepância apresentada entre as percepções dos gerentes, quanto as expectativas dos usuários, e os padrões de qualidade dos serviços prestados, devido a fatores, no tocante aos recursos, como a falta de mecanismos que permitam aos usuários serem ouvidos a respeito das especificações do serviço, bem como a indiferença gerencial, entre outros fatores.

- Gap 3: é entendido como a discrepância entre as especificações do serviço e o serviço que de fato foi entregue, devido a fatores como, colaboradores sem o devido comprometimento, a inabilidade para cumprir o que foi especificado bem como a própria falta de conhecimento das especificações.

- Gap 4: é entendido como a discrepância apresentada entre a qualidade especificada e a qualidade que a prestadora do serviço informa externamente, onde a ocorrência desta discrepância está ligada a falta de comunicação entre usurário e empresa, deixando o usuário sem a noção do que esperar do serviço, além de informações divulgadas que apresentam um serviço com uma qualidade acima do que realmente se entrega. 
- Gap 5: é entendido como a diferença entre a percepção do serviço que realmente a empresa entrega e a expectativa do usuário para a prestação do serviço, onde esta discrepância é um resultado proveniente dos Gaps de 1 a 4.

\section{Service Quality}

O Service Quality ou SERVQUAL é uma escala criada como tentativa de operacionalizar os conhecimentos empíricos da satisfação do usuário de forma a tornarse teoria, com a finalidade de usá-lo como um instrumento capaz de obter a qualidade funcional e que pudesse também ser aplicada em diferentes formas de prestação de serviços (PARASURAMAN, ZEITHAML e BERRY, 1988).

De acordo com Marshall e Murdoch (2001), a escala SERVQUAL original continha uma seção com 22 questões sobre as expectativas do usuário e outra seção também com 22 questões, porém relacionadas a percepção dos usuários quanto ao que realmente foi entregue. Nessa escala, os usuários, submetidos a mesma, deviam avaliar o serviço em uma escala likert, que atribuia notas para cada uma das questões que iam de 1 (discordo totalmente) a 7 (concordo totalmente), por fim somadas as notas das percepções e das expectativas era feita a diferença entre elas, gerando uma nota para mensurar a qualidade do serviço, possibilitando assim a melhoria da mesma.

\section{Estudo de caso}

Nesta seção, serão abordadas as caracterizações da instituição de ensino superior, curso e estudo, apresentação e discursão dos resultados, bem como propostas de melhorias.

\section{Caracterização da IES em estudo}

O estudo foi realizado na Universidade Federal do Pará (UFPA) campus de Abaetetuba, também conhecido como Campus Universitário do Baixo Tocantins, que foi criado no ano de 1987 com o intuito de possibilitar o crescimento da região, através da formação de cidadãos capazes de transformar, socializar e construir uma sociedade mais justa e sustentável. A mesma teve suas atividades iniciadas em parceria com a prefeitura do município, por tanto no início a IES não possuía prédio próprio e suas atividades eram 
desenvolvidas em escolas do município. Somente em 1991 o prédio do campus universitário de Abaetetuba foi inaugurado.

Em 2017 a IES possuía aproximadamente 1800 alunos matriculados nos cursos de Letras (habilitações em língua portuguesa e língua espanhola), Matemática, Engenharia Industrial, Física, Pedagogia e Educação do Campo.

\section{Caracterização do curso em estudo}

O objetivo do curso, segundo seu PPC, é capacitar profissionais para desenvolver atividades técnicas e de gerenciamento, que tornem possível a intervenção nos processos produtivos. Isso faz com que, o papel do Engenheiro Industrial seja fundamental para esses setores da empresa e também contribuem para a melhoria na produtividade e qualidade nas indústrias em geral.

O curso de Bacharelado em Engenharia Industrial teve o ingresso de sua primeira turma no ano de 2009, e desde então, todos os anos são ofertadas 40 novas vagas para o curso. Ele foi vinculado a Faculdade de Ciências Exatas e Tecnologia - FACET até o ano de 2018 quando passou a ser vinculado a Faculdade de Engenharia Industrial - FEI, do Campus Universitário de Abaetetuba, e no ano de 2017 contava com 157 alunos matriculados. O curso é dividido em 10 semestres, e após a conclusão o aluno deverá ter atingido uma carga horaria de 3765 horas.

\section{Apresentação e Discussão dos Resultados}

Na Figura 2, estão apresentados os resultados tabulados dos questionários do modelo SERVQUAL aplicados junto a 106 alunos do curso de Bacharelado em Engenharia Industrial ofertado pela UFPA no Campus de Abaetetuba, referente a satisfação dos mesmos quanto aos serviços prestados pelo curso.

Os resultados expressos pelas percepções e expectativas assinaladas pelos alunos da IES, quanto aos serviços prestados, são comparados por meio da respectiva diferença entre as duas. Esta comparação, utilizando a diferença entre as percepções e expectativas, servem para se determinar parâmetros, pontuando cada item e dimensão. Por meio da pontuação, determina-se as discrepâncias na prestação do serviço, discrepâncias estas, que nesta seção, não devem ser consideradas exclusivamente como problemas, mas sim como oportunidades de melhoria na prestação do serviço avaliado. 
A dimensão capacidade de resposta, itens de 1 a 3, se destacou com o segundo maior Gap médio entre todas as dimensões com um valor de -0,931. O item 3 se destacou com a maior discrepância entre os itens para essa dimensão, com um valor de -1,151, esse item está relacionado ao pronto atendimento das coordenações do curso, estágio e TCC da UFPA e a sua disponibilidade em ajudar os alunos.

A dimensão segurança, questões de 4 a 11, apresentou o menor Gap médio entre as cinco dimensões, com um valor de -0,598. O item 6, para esta dimensão, foi o qual apresentou a maior discrepância estando esse relacionado as atitudes e comportamentos das coordenações do curso, estágio e TCC da UFPA e se as mesmas inspiram confiança na prestação dos seus serviços.

A empatia, itens 12 a 18, apresentou um Gap de -0,708. Os itens 16 e 17 se destacaram com os Gaps -0,925 e -0,906 respectivamente, referente a conveniência dos horários das secretarias e departamentos administrativos, bem como das coordenações do curso, estágio e TCC. Vale destacar ainda, que a dimensão apresentou o item 18 com o menor Gap entre todos os itens distribuídos entre as cinco dimensões, com um valor de 0,094, bem como apresentou o maior valor, 4,094, dentre as médias das percepções. 
Figura 2 - Tabulação dos dados

\begin{tabular}{|c|c|c|c|c|c|c|c|c|c|c|c|c|c|c|}
\hline & \multirow{3}{*}{ Itens } & \multicolumn{6}{|c|}{ Expectativas } & \multicolumn{6}{|c|}{ Percepções } & \multirow{3}{*}{ GAP } \\
\hline & & \multicolumn{5}{|c|}{ Frequência das Respostas } & \multirow{2}{*}{ Média } & \multicolumn{5}{|c|}{ Frequência das Respostas } & \multirow{2}{*}{ Média } & \\
\hline & & 1 & 2 & 3 & 4 & 5 & & 1 & 2 & 3 & 4 & 5 & & \\
\hline \multirow{4}{*}{ 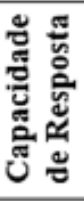 } & 1 & 1 & 5 & 23 & 26 & 51 & 4,142 & 6 & 20 & 42 & 22 & 16 & 3,208 & $-0,934$ \\
\hline & 2 & 1 & 3 & 17 & 32 & 53 & 4,255 & 1 & 11 & 37 & 43 & 14 & 3,547 & $-0,708$ \\
\hline & 3 & 1 & 6 & 13 & 28 & 58 & 4,283 & 5 & 23 & 38 & 33 & 7 & 3,132 & $-1,151$ \\
\hline & \multicolumn{13}{|c|}{ Média da Capacidade de Resposta $=$} & $-0,931$ \\
\hline \multirow{9}{*}{ 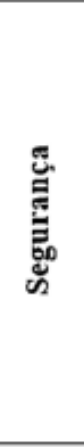 } & 4 & 0 & 1 & 23 & 36 & 46 & 4,198 & 3 & 8 & 24 & 45 & 26 & 3,783 & $-0,415$ \\
\hline & 5 & 0 & 2 & 18 & 30 & 56 & 4,321 & 3 & 3 & 26 & 51 & 23 & 3,830 & $-0,491$ \\
\hline & 6 & 0 & 5 & 21 & 29 & 51 & 4,189 & 3 & 16 & 39 & 36 & 12 & 3,358 & $-0,830$ \\
\hline & 7 & 0 & 5 & 10 & 27 & 64 & 4,415 & 2 & 7 & 19 & 53 & 25 & 3,868 & $-0,547$ \\
\hline & 8 & 0 & 3 & 15 & 30 & 58 & 4,349 & 1 & 10 & 30 & 41 & 24 & 3,726 & $-0,623$ \\
\hline & 9 & 0 & 2 & 17 & 26 & 61 & 4,377 & 2 & 6 & 34 & 46 & 18 & 3,679 & $-0,698$ \\
\hline & 10 & 1 & 3 & 12 & 32 & 58 & 4,349 & 2 & 7 & 31 & 39 & 27 & 3,774 & $-0,575$ \\
\hline & 11 & 0 & 4 & 17 & 22 & 63 & 4,358 & 3 & 9 & 31 & 31 & 32 & 3,755 & $-0,604$ \\
\hline & \multicolumn{13}{|c|}{ Média da Segurança = } & $-0,598$ \\
\hline \multirow{8}{*}{$\begin{array}{l}\text { 丞 } \\
\text { 兽 } \\
\text { 氙 }\end{array}$} & 12 & 0 & 5 & 24 & 36 & 41 & 4,066 & 1 & 12 & 51 & 28 & 14 & 3,396 & $-0,670$ \\
\hline & 13 & 1 & 9 & 19 & 37 & 40 & 4,000 & 2 & 23 & 42 & 28 & 11 & 3,217 & $-0,783$ \\
\hline & 14 & 1 & 7 & 23 & 32 & 43 & 4,028 & 2 & 19 & 41 & 31 & 13 & 3,321 & $-0,708$ \\
\hline & 15 & 3 & 7 & 15 & 26 & 55 & 4,160 & 6 & 22 & 29 & 33 & 16 & 3,292 & $-0,868$ \\
\hline & 16 & 2 & 6 & 21 & 27 & 50 & 4,104 & 7 & 22 & 35 & 29 & 13 & 3,179 & $-0,925$ \\
\hline & 17 & 0 & 7 & 23 & 24 & 52 & 4,142 & 4 & 19 & 43 & 28 & 12 & 3,236 & $-0,906$ \\
\hline & 18 & 3 & 4 & 17 & 28 & 54 & 4,189 & 5 & 6 & 16 & 26 & 53 & 4,094 & $-0,094$ \\
\hline & \multicolumn{13}{|c|}{ Média da Empatia = } & $-0,708$ \\
\hline \multirow{11}{*}{ 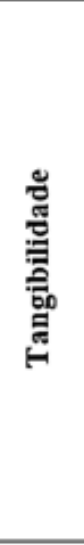 } & 19 & 0 & 3 & 16 & 46 & 41 & 4,179 & 1 & 8 & 22 & 37 & 38 & 3,972 & $-0,208$ \\
\hline & 20 & 1 & 3 & 11 & 45 & 46 & 4,245 & 1 & 7 & 14 & 50 & 34 & 4,028 & $-0,217$ \\
\hline & 21 & 3 & 11 & 17 & 20 & 55 & 4,066 & 11 & 24 & 40 & 22 & 9 & 2,943 & $-1,123$ \\
\hline & 22 & 1 & 6 & 13 & 25 & 61 & 4,311 & 4 & 14 & 17 & 39 & 32 & 3,764 & $-0,547$ \\
\hline & 23 & 5 & 5 & 24 & 26 & 46 & 3,972 & 19 & 24 & 39 & 17 & 7 & 2,708 & $-1,264$ \\
\hline & 24 & 2 & 11 & 16 & 24 & 53 & 4,085 & 6 & 27 & 38 & 26 & 9 & 3,047 & $-1,038$ \\
\hline & 25 & 1 & 3 & 13 & 28 & 61 & 4,368 & 4 & 4 & 19 & 48 & 31 & 3,925 & $-0,443$ \\
\hline & 26 & 2 & 7 & 12 & 31 & 54 & 4,208 & 6 & 22 & 32 & 37 & 9 & 3,198 & $-1,009$ \\
\hline & 27 & 2 & 9 & 17 & 18 & 60 & 4,179 & 7 & 18 & 39 & 29 & 13 & 3,217 & $-0,962$ \\
\hline & 28 & 6 & 11 & 11 & 20 & 58 & 4,066 & 18 & 27 & 35 & 22 & 4 & 2,689 & $-1,377$ \\
\hline & \multicolumn{13}{|c|}{ Média da Tangibilidade = } & $-0,819$ \\
\hline \multirow{8}{*}{ 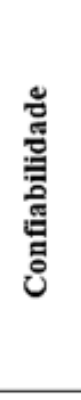 } & 29 & 3 & 5 & 17 & 30 & 51 & 4,142 & 9 & 21 & 45 & 22 & 9 & 3,009 & $-1,132$ \\
\hline & 30 & 2 & 4 & 17 & 28 & 55 & 4,226 & 5 & 17 & 39 & 33 & 12 & 3,283 & $-0,943$ \\
\hline & 31 & 2 & 5 & 24 & 30 & 45 & 4,047 & 3 & 29 & 37 & 28 & 9 & 3,104 & $-0,943$ \\
\hline & 32 & 0 & 2 & 25 & 34 & 45 & 4,151 & 2 & 9 & 35 & 52 & 8 & 3,519 & $-0,632$ \\
\hline & 33 & 2 & 9 & 21 & 28 & 46 & 4,009 & 9 & 21 & 50 & 19 & 7 & 2,943 & $-1,066$ \\
\hline & 34 & 4 & 4 & 21 & 33 & 44 & 4,028 & 7 & 16 & 34 & 33 & 16 & 3,330 & $-0,698$ \\
\hline & 35 & 3 & 11 & 18 & 19 & 55 & 4,057 & 14 & 26 & 46 & 14 & 6 & 2,736 & $-1,321$ \\
\hline & \multicolumn{13}{|c|}{ Média da Confiabilidade $=$} & $-0,962$ \\
\hline & & & & & & 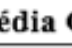 & $\mathbf{r a l}=$ & $-0,8$ & & & & & & \\
\hline
\end{tabular}

Fonte: Elaboração dos Autores (2018). 
A tangibilidade, itens de 19 a 28, apresentou um Gap médio de -0,819. Os itens 21, 23 e 28 se destacaram, entre todos os itens, para esta dimensão. Sendo que, o item 28 obteve um Gap com magnitude de -1,377, a maior discrepância entre todos os itens distribuídos no questionário, apresentando ainda a menor média, 2,689, dentre todas as percepções, abordando a avaliação quanto a qualidade e quantidade de equipamentos nos laboratórios do curso de engenharia industrial. Os outros dois itens, 21 e 23, relevantes a esta dimensão, obtiveram os Gaps -1,123, -1,264 respectivamente, abordando a avaliação quanto a qualidade e quantidade do acervo da biblioteca, assim como o espaço o serviço e a qualidade dos produtos da cantina.

A dimensão confiabilidade, itens 29 a 35, apresentou um Gap médio de -0,962 a maior discrepância entre as cinco dimensões que constituem o questionário. Nessa dimensão, percebe-se que os itens 29 e 35, apresentaram as maiores discrepâncias, com um valor de -1,132 e de -1,321 respectivamente, essas discrepâncias estão relacionadas a prestação de serviços em prazos adequados, informes quanto ao andamento de suas solicitações e processos, bem como a divulgação de eventos e serviços de interesse dos alunos.

Figura 3 - GAPs médios por dimensão

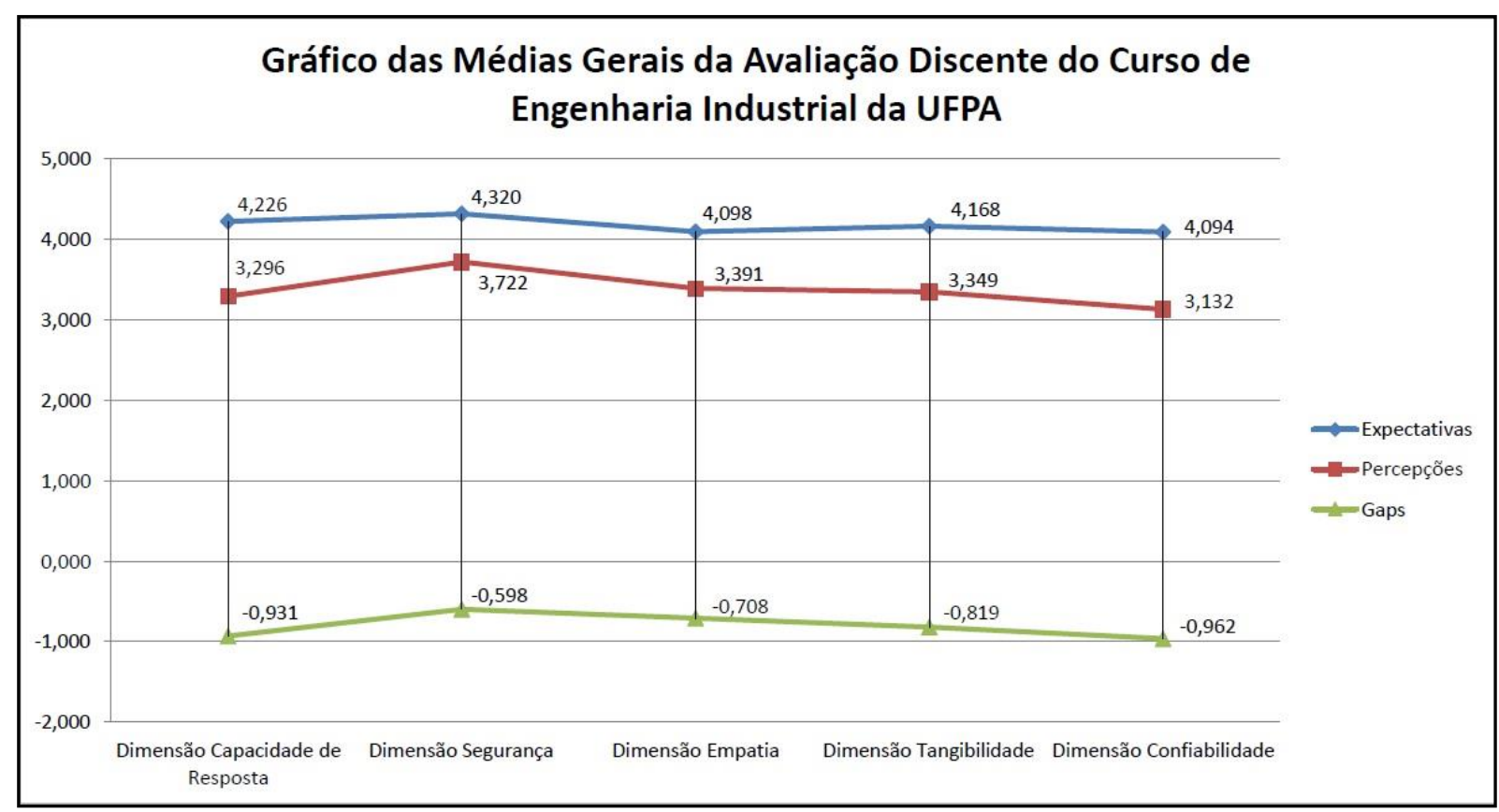

Fonte: Elaboração dos Autores (2018). 
Os resultados apresentaram um Gap médio geral, para as cinco dimensões, de 0,803. Entre as dimensões, como se observa na figura 3 , a confiabilidade foi a que apresentou a maior discrepância com a média de -0,962, com as outras quatro dimensões compondo, na ordem decrescente dos valores dos Gaps, a seguinte classificação: capacidade de resposta com -0,931, tangibilidade com -0,819, empatia com -0,708 e segurança com -0,598. Os Gaps expostos, confirmam oportunidades de melhorias no sistema de prestação de serviços do curso de Bacharelado em Engenharia Industrial alvo do presente estudo.

\section{Propostas de melhoria}

Como proposta de melhoria verificando os resultados dos Gaps sugere-se a aplicação da ferramenta da qualidade $5 \mathrm{~W} 1 \mathrm{H}$ para sugerir planos que sejam evitados e prevenidos.

O 5W1H é um checklist, é uma ferramenta utilizada para garantir que os procedimentos sejam realizados sem nenhuma dúvida tanto por parte dos gerentes quanto por seus subordinados, para definir as tarefas de cada um de forma clara e objetiva para que o plano de melhoria siga todas as etapas corretamente (PEINADO \& GRAEML, 2007).

Tabela 1 - Plano de Melhorias para o Curso

\begin{tabular}{|c|c|c|c|c|c|}
\hline What (O quê?) & $\begin{array}{l}\text { Who } \\
\text { (Quem?) }\end{array}$ & $\begin{array}{l}\text { Where } \\
\text { (Onde?) }\end{array}$ & $\begin{array}{l}\text { When } \\
\text { (Quando?) }\end{array}$ & $\begin{array}{l}\text { Why } \\
\text { (Porquê?) }\end{array}$ & $\begin{array}{l}\text { How } \\
\text { (Como?) }\end{array}$ \\
\hline $\begin{array}{l}\text { Criar equipes } \\
\text { para realizar } \\
\text { atendimentos } \\
\text { em horários } \\
\text { especiais }\end{array}$ & $\begin{array}{l}\text { Secretaria e } \\
\text { coordenação } \\
\text { do curso }\end{array}$ & $\begin{array}{l}\text { Secretaria e } \\
\text { gabinetes } \\
\text { dos } \\
\text { responsáveis }\end{array}$ & Imediatamente & $\begin{array}{lr}\text { Por algumas } \\
\text { turmas serem } \\
\text { no período da } \\
\text { noite e } \\
\text { coordenação e } \\
\text { secretaria do } \\
\text { curso } \\
\text { funcionarem no } \\
\text { horário } \\
\text { comercial, se } \\
\text { torna } \\
\text { necessário que } \\
\text { se tenha uma } \\
\text { equipe } \\
\text { disponível para } \\
\text { atender } \\
\text { demanda dos }\end{array}$ & $\begin{array}{l}\text { Utilizando o } \\
\text { sistema de } \\
\text { turno e folgas }\end{array}$ \\
\hline
\end{tabular}




\begin{tabular}{|c|c|c|c|c|c|}
\hline & & & & $\begin{array}{l}\text { alunos do turno } \\
\text { da noite }\end{array}$ & \\
\hline $\begin{array}{l}\text { Realizar } \\
\text { treinamentos e } \\
\text { reuniões } \\
\text { informativas } \\
\text { para agilizar o } \\
\text { atendimento }\end{array}$ & $\begin{array}{l}\text { Coordenação } \\
\text { e secretaria do } \\
\text { curso }\end{array}$ & Auditório & A cada 30 dias & $\begin{array}{l}\text { Para atualizar } \\
\text { os } \\
\text { coordenadores } \\
\text { e secretários } \\
\text { sobre as } \\
\text { transições e } \\
\text { acontecimentos } \\
\text { da instituição e } \\
\text { principalmente } \\
\text { as quais afetam } \\
\text { o curso } \\
\end{array}$ & $\begin{array}{l}\text { Com o apoio } \\
\text { do diretor e } \\
\text { coordenadores }\end{array}$ \\
\hline $\begin{array}{l}\text { Implantar uma } \\
\text { Campanha de } \\
\text { doação de livros }\end{array}$ & $\begin{array}{l}\text { Coordenação } \\
\text { do curso, } \\
\text { Centro } \\
\text { Acadêmico do } \\
\text { curso e } \\
\text { biblioteca }\end{array}$ & $\begin{array}{l}\text { No campus } \\
\text { da } \\
\text { instituição }\end{array}$ & Anualmente & \begin{tabular}{lr}
\multicolumn{2}{l}{ Para incentivar } \\
professores & e \\
alunos & a \\
realizar & \\
doações & de \\
livros & \\
referentes & ao \\
curso & \\
\end{tabular} & $\begin{array}{l}\text { Com o apoio } \\
\text { dos } \\
\text { coordenadores } \\
\text { e alunos }\end{array}$ \\
\hline $\begin{array}{l}\text { Garantir que a } \\
\text { prestação de } \\
\text { serviços de } \\
\text { atendimento } \\
\text { será feita no } \\
\text { prazo adequado } \\
\text { pela secretaria e } \\
\text { coordenação }\end{array}$ & $\begin{array}{l}\text { Secretaria e } \\
\text { coordenação } \\
\text { do curso }\end{array}$ & $\begin{array}{l}\text { Secretaria e } \\
\text { gabinetes } \\
\text { dos } \\
\text { responsáveis }\end{array}$ & $\begin{array}{l}\text { Único } \\
\text { treinamento } \\
\text { para os } \\
\text { funcionários e, } \\
\text { posteriormente, } \\
\text { eventualmente } \\
\text { para } \\
\text { funcionários } \\
\text { novos }\end{array}$ & \begin{tabular}{|lr} 
Criar & um \\
sistema & de \\
entrada e & saída \\
de processos \\
facilitará & o \\
andamento & de \\
solicitações & \\
realizadas r pela \\
sua ordem \\
entrada e pelo \\
seu grau de \\
importância
\end{tabular} & $\begin{array}{l}\text { Utilizando } \\
\text { sistema de } \\
\text { filas como } \\
\text { FIFO e grau } \\
\text { de prioridades } \\
\text { seguindo o } \\
\text { treinamento } \\
\text { ministrado }\end{array}$ \\
\hline $\begin{array}{l}\text { Tornar o serviço } \\
\text { de informação } \\
\text { por telefone } \\
\text { confiável }\end{array}$ & $\begin{array}{l}\text { Equipe de TI e } \\
\text { Consultor } \\
\text { especialista } \\
\text { em } \\
\text { atendimento } \\
\text { ao cliente }\end{array}$ & $\begin{array}{l}\text { Auditório da } \\
\text { instituição }\end{array}$ & A cada 6 meses & $\begin{array}{l}\text { Para passar } \\
\text { mais segurança } \\
\text { e credibilidade } \\
\text { nas } \\
\text { informações } \\
\text { fornecidas pelo } \\
\text { atendimento }\end{array}$ & $\begin{array}{l}\text { Fazendo } \\
\text { treinamento } \\
\text { de } \\
\text { telemarketing } \\
\text { e de sistema } \\
\text { interno }\end{array}$ \\
\hline $\begin{array}{l}\text { Aperfeiçoar o } \\
\text { sistema interno }\end{array}$ & Equipe de TI & $\begin{array}{l}\text { Laboratório } \\
\text { de } \\
\text { informática }\end{array}$ & $\begin{array}{l}\text { A cada } \\
\text { semanas }\end{array}$ & $\begin{array}{l}\text { A interface do } \\
\text { sistema interno } \\
\text { das instituições } \\
\text { sempre } \\
\text { atualizado faz } \\
\text { com que evitem } \\
\text { certos }\end{array}$ & $\begin{array}{l}\text { Melhorando a } \\
\text { sistematização } \\
\text { de pedidos } \\
\text { online para } \\
\text { torna-lo mais } \\
\text { confiável }\end{array}$ \\
\hline
\end{tabular}




\begin{tabular}{|c|c|c|c|c|c|}
\hline & & & & $\begin{array}{l}\text { procedimentos } \\
\text { e serviços } \\
\text { desnecessários }\end{array}$ & \\
\hline $\begin{array}{lr}\text { Melhorar } & \text { a } \\
\text { divulgação } & \text { do } \\
\text { curso } & \end{array}$ & $\begin{array}{l}\text { Grupo } \\
\text { acadêmico } \\
\text { definido pelos } \\
\text { acadêmicos e } \\
\text { coordenadores } \\
\text { do curso }\end{array}$ & $\begin{array}{l}\text { Laboratório } \\
\text { de } \\
\text { informática }\end{array}$ & Semanalmente & $\begin{array}{lr}\text { Realizar } & \text { a } \\
\text { divulgação do } & \text { curso é de suma } \\
\text { importância } & \\
\text { para } & \\
\text { reconhecimento }\end{array}$ & $\begin{array}{l}\text { Escrevendo } \\
\text { artigos para } \\
\text { jornais e redes } \\
\text { sociais }\end{array}$ \\
\hline
\end{tabular}

Fonte: Elaboração dos Autores (2018).

Selecionando os Gaps com os piores valores negativos se elaborou a tabela do $5 \mathrm{~W} 1 \mathrm{H}$ propondo planos de melhoria para as maiores reclamações dos discentes do curso como mostra a tabela 1 .

Vale ressaltar que no $5 \mathrm{~W} 1 \mathrm{H}$ da tabela 1 foram trabalhados os Gaps com os piores valores negativos, acima de $-0,965$, pois se encontram com maior índice de insatisfação.

\section{Considerações finais}

O presente estudo teve como objetivo a avaliação do nível de satisfação dos alunos do curso de Bacharelado em Engenharia Industrial da Universidade Federal do Pará, Campus de Abaetetuba, utilizando uma ferramenta da qualidade que realiza uma quantificação da qualidade em prestação de serviços.

O método SERVQUAL, utilizado neste trabalho, apresentou a dimensão confiabilidade como a dimensão com maior discrepância dentre todas as dimensões utilizadas neste artigo, com uma média geral de (-0,960), a ordem decrescente de classificação, quanto as discrepâncias seguiu com as dimensões, capacidade de resposta $(-0,931)$, tangibilidade $(-0,819)$, empatia $(-0,708)$, e segurança $(-0,598)$.

Com os resultados, nota-se que todas as cincos dimensões apresentaram valores negativos para os seus Gaps, entre outras palavras, conclui-se que as percepções assinaladas pelos alunos do curso estão abaixo de suas expectativas, demonstrando falhas nas prestações de serviços do curso.

A utilização da ferramenta 5W1H mostrou uma forma pratica de se trabalhar os principais pontos negativos avaliados na pesquisa e elaborar planos de ação para evitar 
tais itens. Destaca-se que mesmo o item DTang28 tendo apresentado um Gap de magnitude (-1,377), maior lacuna que estava relacionada com "os laboratórios específicos do curso de Engenharia Industrial possuírem equipamentos e recursos modernos, atuais, de boa qualidade e quantidade", este não foi trabalhado no plano de melhorias por precisar de recursos financeiros. Deste modo, apesar de ter apresentado o maior grau de insatisfação por parte dos discentes e de não ter sido mencionado no plano de melhorias este item deve ser tratado com certa prioridade pela administração do campus e do curso em estudo assim que se tenha recursos financeiros disponíveis.

Como descrito na seção anterior, o presente trabalho vislumbra a oportunidade de melhoria na prestação do serviço do curso em questão, assim, pôde-se perceber como a ferramenta SERVQUAL proporciona o diagnóstico de problemas na prestação de serviço, focado a uma tomada de decisão que busca a melhoria e a qualidade em serviços.

\section{Referências}

CARPINETTI, L. C. R.; GEROLAMO, M. C. Gestão da Qualidade ISO 9001: 2015 Requisitos e Integração com a ISO 14001:2015. São Paulo: Atlas, 2016.

CARVALHO, M. M.; PALADINI, E. P. Gestão da Qualidade - Teoria e Casos. 2 ed. Rio de Janeiro: Campus, 2012.

FITZSIMMONS, J. A. \& FITZSIMMONS, M. J. Administração de Serviços: Operações, Estratégia e Tecnologia de Informação. 5 ed. Porto Alegre: Bookman, 2007.

GRÖNROOS, C. Marketing, Gerenciamento e Serviços: a competição por serviços na hora da verdade. Rio de Janeiro: Campus, 1993.

LAS CASAS, A. L. Qualidade total em serviços: conceitos, exercícios, casos práticos. 2 ed. São Paulo: Atlas, 1997.

MARQUES, D.; PIERRE, F. C. Aplicação do modelo SERVQUAL para avaliar a qualidade do serviço da biblioteca de uma Instituição de Ensino Superior na região de Botucatu. Tekhne e Logos, Botucatu, SP, v.5, n.2, Dezembro, 2014.

MARSHALL G.; MURDOCH, I. Service quality in consulting marketing engineers. Int J Constr Mark, 2001. 
MARTINS, P. G.; LAUGENI, F. P. Administração da produção. 3. ed. São Paulo: Saraiva, 2015.

OLIVEIRA, O. J., \& FERREIRA, E. C. Adaptação e aplicação da escala SERVQUAL na educação superior. Gestão da Produção, Operações e Sistemas - GEPROS, n.3, vol. 3, p. 133-146, 2008.

PARASURAMAN, A., ZEITHAML V. A., BERRY, L. L. A conceptual model of services quality and its implication for future research. Journal of Marketing, v. 49, $\mathrm{n}^{\circ}$ 4, p. 41-50, 1985.

PARASURAMAN, A.; BERRY, L. L.; ZEITHAML, V.A. Refinement and reassessement of the SERVQUAL dimensions. Journal of Retailing, 1991.

PARASURAMAN, A.; ZEITHAML, V. A.; BERRY, L. L. Servqual: A multiple-item scale for measuring consumer perceptions of service quality. Journal of Retailing, v.64, n. 1, p. 12-40, 1988.

PENA, M. M.; SILVA, E. M. S.; TRONCHIN, D. M. R.; MELLEIRO, M. M. O emprego do modelo de qualidade de Parasuraman, Zeithaml e Berry em serviços de saúde. Revista da Escola de Enfermagem da USP, v.47, n.5, p.1227-1232, 2013.

PEINADO, J., GRAEML, A. R., Adiministração da produção: operações e serviços, Curitiba: UnicenP, 20017 


\section{Apêndice A - Questionário de Expectativas e Percepções}

\begin{tabular}{|c|c|c|}
\hline & Expectativa & Percepção \\
\hline 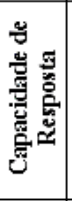 & $\begin{array}{l}\text { 1-Haver um pronto atendimento dos funcionários da UFPA e estes } \\
\text { estarem sempre dispostos a ajudar. } \\
\text { 2-Haver um pronto atendimento dos professores da UFPA e estes } \\
\text { estarem sempre dispostos a ajudar. } \\
\text { 3- Haver um pronto atendimento das coordenações (de curso, } \\
\text { estágio e TCC) da UFPA e estas estarem sempre dispostas a ajudar. }\end{array}$ & $\begin{array}{l}\text { 1-Há um pronto atendimento dos funcionários da UFPA e estes } \\
\text { estão sempre dispostos a ajudar. } \\
\text { 2-Há um pronto atendimento dos professores da UFPA e estes } \\
\text { estão sempre dispostos a ajudar. } \\
\text { 3-Há um pronto atendimento das coordenações (de curso, } \\
\text { estágio e TCC) da UFPA e estas estão sempre dispostas a } \\
\text { ajudar. }\end{array}$ \\
\hline $\begin{array}{l}\text { 总 } \\
\text { 窟 } \\
\text { 品 }\end{array}$ & $\begin{array}{l}\text { 4- As atitudes e comportamentos dos funcionários da UFPA } \\
\text { inspirarem confiança nos serviços prestados. } \\
5 \text { - As atitudes e comportamentos dos professores da UFPA } \\
\text { inspirarem confiança nos serviços prestados. } \\
\text { 6- As atitudes e comportamentos das coordenações (de curso, } \\
\text { estágio e TCC) da UFPA inspirarem confiança nos serviços } \\
\text { prestados. } \\
7 \text { - Os professores terem conhecimentos adequados para } \\
\text { desempenhar suas funções. } \\
\text { 8- Os funcionários terem conhecimentos adequados para } \\
\text { desempenhar suas funções. } \\
\text { 9- As coordenações terem conhecimentos adequados para } \\
\text { desempenhar suas funções. } \\
\text { 10- Os professores, funcionários e coordenações tratarem os alunos } \\
\text { de modo cortês. } \\
\text { 11- Você se sentir mais seguro e confiante (na sua formação, } \\
\text { reconhecimento do mercado profissional e segurança física) por } \\
\text { estar estudando na UFPA. }\end{array}$ & $\begin{array}{l}\text { 4- As atitudes e comportamentos dos funcionários da UFPA } \\
\text { inspiram confiança nos serviços prestados. } \\
\text { 5- As atitudes e comportamentos dos professores da UFPA } \\
\text { inspiram confiança nos serviços prestados. } \\
\text { 6- As atitudes e comportamentos das coordenações (de curso, } \\
\text { estágio e TCC) da UFPA inspiram confiança nos serviços } \\
\text { prestados. } \\
\text { 7- Os professores demonstram ter conhecimentos adequados } \\
\text { para desempenhar suas funções. } \\
\text { 8- Os funcionários demonstram ter conhecimentos adequados } \\
\text { para desempenhar suas funções. } \\
\text { 9- As coordenações demonstram ter conhecimentos adequados } \\
\text { para desempenhar suas funções. } \\
\text { 10- Os professores, funcionários e coordenações tratam os } \\
\text { alunos de modo cortês. } \\
\text { 11- Você se sente mais seguro e confiante (na sua formação, } \\
\text { reconhecimento do mercado profissional e segurança física) } \\
\text { por estar estudando na UFPA. }\end{array}$ \\
\hline & $\begin{array}{l}\text { 12- A equipe de professores fornecer uma adequada atenção } \\
\text { individual. } \\
\text { 13- O pessoal de apoio (funcionários em geral, secretarias, } \\
\text { pedagoga e etc.) prestar uma adequada atenção individual. } \\
\text { 14- As coordenações fornecerem uma adequada atenção individual. } \\
\text { 15- A UFPA possuir horários de aula convenientes. } \\
\text { 16- As secretarias e departamentos administrativos da UFPA } \\
\text { possuírem horários convenientes. } \\
\text { 17- As coordenações (curso, estágio e TCC) possuirem horários } \\
\text { convenientes. } \\
\text { 18- O tempo de duração do curso ( } 5 \text { anos) ser conveniente. }\end{array}$ & $\begin{array}{l}\text { 12- A equipe de professores fornece uma adequada atenção } \\
\text { individual. } \\
\text { 13- O pessoal de apoio (funcionários em geral, secretarias, } \\
\text { pedagoga e etc.) presta uma adequada atenção individual. } \\
\text { 14- As coordenações fornecem uma adequada atenção } \\
\text { individual. } \\
\text { 15- A UFPA possui horários de aula convenientes. } \\
\text { 16- As secretarias e departamentos administrativos da UFPA } \\
\text { possuem horários convenientes. } \\
\text { 17- As coordenações (curso, estágio e TCC) possuem horários } \\
\text { convenientes. } \\
\text { 18- O tempo de duração do curso ( } 5 \text { anos) é conveniente. }\end{array}$ \\
\hline 旁 & $\begin{array}{l}\text { 19- Os funcionários possuírem uma aparência e postura } \\
\text { profissional adequadas. } \\
20 \text { - Os professores e coordenadores possuírem uma aparência e } \\
\text { postura profissional adequadas. } \\
21 \text { - A qualidade e quantidade do acervo da biblioteca serem } \\
\text { adequadas. } \\
22-\text { As instalações em geral (corredores, área đe bate-papo, } \\
\text { banheiros) da UFPA possuirem bom asseio, conservação e aspecto } \\
\text { visual. } \\
23 \text { - O espaço, serviço e qualidade dos produtos da cantina serem } \\
\text { adequados. } \\
24-\text { O espaço, serviço e qualidade dos produtos do centro de cópias } \\
\text { e impressão serem adequados. } \\
25-\text { As salas de aula possuirem um tamanho adequado ao número } \\
\text { de alunos e estarem com um adequado estado de conservação, } \\
\text { climatização e isolamento acústico. } \\
26 \text { - Os equipamentos e materiais utilizados (recursos audiovisuais, } \\
\text { cópias e etc.) nas aulas em sala serem modernos, atuais e } \\
\text { visualmente atraentes. } \\
27-\text { Os laboratórios de informática possuirem equipamentos e } \\
\text { recursos modernos, atuais, de boa qualidade e quantidade. } \\
28-\text { Os laboratórios específicos do curso de Engenharia Industrial } \\
\text { possuirem equipamentos e recursos modernos, atuais, de boa } \\
\text { qualidade e quantidade. }\end{array}$ & $\begin{array}{l}\text { 19- Os funcionários possuem uma aparência e postura } \\
\text { profissional adequadas. } \\
20 \text { - Os professores e coordenadores possuem uma aparência e } \\
\text { postura profissional adequadas. } \\
21 \text { - A qualidade e quantidade do acervo da biblioteca são } \\
\text { adequadas. } \\
\text { 22- As instalações em geral (corredores, área de bate-papo, } \\
\text { banheiros) da UFPA possuem bom asseio, conservação e } \\
\text { aspecto visual. } \\
\text { 23- O espaço, serviço e qualidade dos produtos da cantina são } \\
\text { adequados. } \\
24-\text { O espaço, serviço e qualidade dos produtos do centro de } \\
\text { cópias e impressão são adequados. } \\
\text { 25- As salas de aula possuem um tamanho adequado ao } \\
\text { número de alunos e estão em adequado estado de conservação, } \\
\text { climatização e isolamento acústico. } \\
\text { 26- Os equipamentos e materiais utilizados (recursos } \\
\text { audiovisuais, cópias e etc.) nas aulas em sala são modernos, } \\
\text { atuais e visualmente atraentes. } \\
\text { 27- Os laboratórios de informática possuem equipamentos e } \\
\text { recursos modernos, atuais, de boa qualidade e quantidade. } \\
28-\text { Os laboratórios específicos do curso de Engenharia } \\
\text { Industrial possuem equipamentos e recursos modernos, atuais, } \\
\text { de boa qualidade e quantidade. }\end{array}$ \\
\hline 曾 & $\begin{array}{l}\text { 29- Os setores administrativos da UFPA prestarem serviços em } \\
\text { prazos adequados e o informarem do andamento de suas } \\
\text { solicitações e processos. } \\
\text { 30- Os professores prestarem seus serviços (aulas, correção de } \\
\text { provas e trabalhos, datas de avaliações) no prazo combinado. } \\
\text { 31- Os setores administrativos da UFPA executarem seus serviços } \\
\text { corretamente logo na primeira vez. } \\
\text { 32- Os professores executarem seus serviços corretamente logo na } \\
\text { primeira vez. } \\
\text { 33- O pedido de informação por telefone ser acessivel e confiável. } \\
\text { 34- As informações e solicitações pelos links, páginas de internet e } \\
\text { sistemas on-line serem eficazes e confiáveis. } \\
\text { 35- A UFPA e o curso de Engenharia Industrial fazerem uma boa } \\
\text { divulgação sobre eventos e serviços de interesse aos alunos. }\end{array}$ & $\begin{array}{l}\text { 29- Os setores administrativos da UFPA prestam serviços em } \\
\text { prazos adequados, e o informam do andamento de suas } \\
\text { solicitações e processos. } \\
\text { 30- Os professores prestam seus serviços (aulas, correção de } \\
\text { provas e trabalhos, datas de avaliações) no prazo combinado. } \\
\text { 31- Os setores administrativos da UFPA executam seus } \\
\text { serviços corretamente logo na primeira vez. } \\
\text { 32- Os professores executam seus serviços corretamente logo } \\
\text { na primeira vez. } \\
\text { 33- O pedido de informação por telefone é acessivel e } \\
\text { confiável. } \\
\text { 34- As informações e solicitações pelos links, páginas de } \\
\text { internet e sistemas on-line são eficazes e confiáveis. } \\
\text { 35- A UFPA e o curso de Engenharia Industrial fazem uma boa } \\
\text { divulgação sobre eventos e serviços de interesse aos alunos. }\end{array}$ \\
\hline
\end{tabular}

Fonte: Elaboração dos Autores (2018). 